\title{
Effect of smoking and comorbidities on survival in idiopathic pulmonary fibrosis
}

\author{
Miia Kärkkäinen ${ }^{1,2^{*}}$, Hannu-Pekka Kettunen ${ }^{3}$, Hanna Nurmi ${ }^{2,4}$, Tuomas Selander ${ }^{5}$, Minna Purokivi ${ }^{1}$ \\ and Riitta Kaarteenaho $0^{1,2,6}$
}

\begin{abstract}
Background: Cigarette smoking has been associated with the risk of idiopathic pulmonary fibrosis (IPF). Certain comorbidities have been associated with reduced survival although some studies have indicated that current smokers have a longer survival than ex-smokers. Comorbidities in relation to smoking history have not been previously analyzed.

Methods: Retrospective data was collected and patients were categorized according to gender and smoking habits. Comorbidities and medications were collected. Predictive values for mortality were identified by COX proportional hazard analyses.

Results: We examined 45 non-smokers (53.3\% female), 66 ex-smokers ( $9.1 \%$ female) and 17 current smokers (17.6\% female) with IPF. Current smokers were younger at baseline (58.1 \pm 8.74 years) compared to non-smokers $(71.4 \pm 8.74, p$ $<0.001)$ and ex-smokers $(72.5 \pm 7.95, p<0.001)$. Median survival of non-smokers and current smokers was longer (55.0 and 52.0 months, respectively) than that of ex-smokers (36.0 months) ( $\mathrm{p}=0.028$ and 0.034 , respectively). In age and severity adjusted analyses, smoking was not related to survival. Cardiovascular diseases (CVD) (72.7\%) were the most common comorbidities, current smokers had more chronic obstructive pulmonary disease (COPD) and lung cancer compared to ex-smokers ( $p<0.001)$. CVD, COPD and use of insulin were related to poorer survival in adjusted analyses.

Conclusions: Smoking seems to influence the course of disease in IPF since current smokers developed the disease at a younger age in comparison to non-smokers and ex-smokers. No significant differences in the major comorbidities were detected between IPF patients with different smoking histories. The mechanism through which smoking influences IPF progression requires further investigation.
\end{abstract}

Keywords: Idiopathic pulmonary fibrosis, smoking, gender, comorbidity

\section{Background}

Cigarette smoking has been shown to associate with the risk of developing idiopathic pulmonary fibrosis (IPF) with ever-smokers having a $60 \%$ higher risk [1]. There are, however, controversial reports on how smoking affects survival in IPF. Current smokers at the time of IPF diagnosis have been found to have longer survival times than ex-smokers as well as non-smokers and ex-

\footnotetext{
* Correspondence: miia.karkkainen@kuh.fi

${ }^{1}$ The Center of Medicine and Clinical Research, Division of Respiratory Medicine, Kuopio University Hospital, P.O. Box 100, 70029 KYS,

Puijonlaaksontie 2, 70210 Kuopio, Finland

${ }^{2}$ Division of Respiratory Medicine, Institute of Clinical Medicine, School of Medicine, Faculty of Health Sciences, University of Eastern Finland, P.O. Box 1627, 70211 Kuopio, Finland

Full list of author information is available at the end of the article
}

smokers; however, if one applies the composite physiologic index (CPI) for severity adjustment, then neversmokers had longer survival times than ever-smokers (i.e. current and ex-smokers) and furthermore the survival difference between current and ex-smokers disappeared [2, 3]. A recent study found that ever-smokers with IPF lived longer than never-smokers who, however, revealed significantly higher CPI and thus severity adjusted survival remained significantly different between the two groups [4]. Males with current or past smoking histories and occupational exposure have been reported to carry an increased risk of IPF compared to nonexposed females [5].

In addition to smoking, comorbidities might influence the progression of IPF i.e. patients with several comorbidities 
have been shown to exhibit worse survival than those not burdened by comorbidities [6]. The most prevalent comorbidities in IPF have been shown to be pulmonary hypertension, obstructive sleep apnea (OSA), lung cancer, chronic obstructive pulmonary disease (COPD), coronary artery disease (CAD) and gastro-esophageal reflux (GER) [7]. Furthermore, IPF-patients have been reported to have an increased risk of vascular disease, diabetes and hypertension [6, 8-10]. Thyroid disease, diabetes, CAD and lung cancer are all illnesses that have been shown to associate with shortened survival in IPF, whereas the use of GER medication has been claimed to prolong patient lifespans [10-15]. The results on the use of statin and anticoagulant medications on the survival of IPF patients have been controversial [10, 16-19].

The aims of this study were to evaluate the clinical and radiological characteristics of patients with IPF in a retrospective cohort from an eastern Finnish Hospital and to subdivide them according to smoking history i.e. nonsmokers, ex-smokers and current smokers in both the whole study group, and also separately for female and male patients. Furthermore, we wanted to examine the numbers and types of comorbidities and medications, and evaluate their effect on survival of the patients.

\section{Materials and Methods}

\section{Patients and data collection}

A total of 223 patients (91 female, 132 male) with pulmonary fibrosis treated in Kuopio University Hospital between $1^{\text {st }}$ January 2002 and $31^{\text {st }}$ December 2012 were collected from medical records of the hospital by using International Classification of Diseases version 10 (ICD10) codes J84.1, J84.8 and J84.9. Clinical, radiological and histological information of each patient was transferred from medical records to special data collection forms designed for the present study. Pulmonary fibroses with a known etiology, i.e. connective-tissue disease, occupational exposure etc., were excluded. The data concerning comorbidities and survival was updated on $16^{\text {th }}$ October 2016.

Smoking status was categorized as non-smoker, exsmoker and current smoker and collected as years, packyears or both if available. Ex-smokers were defined as having smoked regularly for more than one year, and longitudinal changes in smoking habits after the diagnosis of IPF were not considered. The presence of comorbid diseases i.e. COPD, asthma, hypertension, heart failure for any reason, $\mathrm{CAD}$, cerebral infarction, transient ischemic attacks, OSA, lung cancer, GER, depression, diabetes and other cancers were gathered from the medical records; in this case the time of diagnosis was the cut-off for subdivision into either before or after the diagnosis of IPF. Pulmonary function tests (PFT) included results of spirometry i.e. forced vital capacity
(FVC), forced expiratory volume in one second (FEV1) and FEV1/FVC ratio, diffusion capacity i.e. diffusion capacity of carbon monoxide (DLco) and potential value of diffusion capacity per liter of lung volume (DLco/VA). PFT results were expressed as absolute numerical values and percentages of predicted values. Information from histological samples from surgical lung biopsy or autopsy was gathered.

No consents for inclusion into this study were gathered since this was a retrospective study and the majority of the patients are deceased. The study protocol was approved by the Ethical Committee of Kuopio University Hospital (statement 17/2013) and from the National Institute for Health and Welfare (Dnro THL/1052/5.05.01/2013). Permission to use data from death certificates was given by Statistics Finland (Dnro: TK-53-911-13). This study was conducted in compliance with the Declaration of Helsinki.

\section{Assessment of clinical, radiological and histological data} The PFT were evaluated using the Finnish reference values [20]. CPI was calculated from the PFT results as follows: $91.0-(0.65 \times$ \% predicted DLco $)-(0.53 \times \%$ predicted FVC $)+(0.34 \times \%$ predicted FEV1 $)$ [21]. The findings of the first and last high resolution computed tomography (HRCT) of each patient were re-evaluated by a radiologist according to the recent statement of the American Thoracic Society (ATS) and European Respiratory Society (ERS) and re-classified as usual interstitial pneumonia (UIP), possible UIP and not UIP [22]. All the patients whose re-analyses were categorized as not definite UIP in HRCT were evaluated by a multidisciplinary discussion with a radiologist, a pathologist and a pulmonologist before being included into the present study. Either death or lung transplantation were considered as end-points in the survival analyses.

\section{Statistical analysis}

Statistical analysis was performed with IBM SPSS Statistics version 21. Group differences were tested by KruskallWallis or Mann-Whitney U-test for continuous variables and by Chi-square testing or Fisher exact test for categorical variables. Data is presented as mean with standard deviation for continuous variables or frequencies with percentages when variables are categorical. Survival curves were estimated by the Kaplan-Meier method and differences in survival were compared using log-rank test, in addition median survival is expressed. Univariate and multivariate survival analysis were computed using Cox regression models. Results from Cox survival analyses are shown in the form of a hazard ratio with $95 \%$ confidence intervals. An ordered logistic regression was performed in order to evaluate the impact of age and smoking status on the number of comorbidities. P-value $<0.05$ was considered as statistically significant. 


\section{Results}

\section{Demographics and unadjusted survival}

A total of 132 patients with IPF were evaluated in this study; of these, 97 (73.5\%) were male and 35 (26.5\%) female. The mean age of the patients at the time of diagnosis was 70.5 years and the median survival 45.0 months. When we updated the data $\left(16^{\text {th }}\right.$ October 2016), a total of 115 patients had deceased and 15 patients were still alive. Three patients (one of whom had died) had undergone lung transplantation. Two males and 2 females had an unknown smoking history. From the 128 (96.7\%) patients with a known smoking history, 45 (35.2\%) were non-smokers, 66 (51.2\%) ex-smokers and $17(13.4 \%)$ were current smokers. There were more female non-smokers $(\mathrm{p}<0.001)$ and fewer ex-smokers than their male counterparts ( $p<0.001$ ) but no gender difference was seen in the proportion of current smokers $(\mathrm{p}=0.410)$. Current smokers had smoked for significantly more years and more pack-years than ex-smokers and they were also significantly younger at the time of diagnosis and at death compared to non-smokers and exsmokers; this remained the case when male patients were analyzed separately. Current smoker females were younger at the time of diagnosis compared to exsmoking females (0.036) and they died at a younger age than their non-smoking counterparts $(p=0.038)$. Female patients had significantly longer survival time compared to males, 42.2 months and 29.1 months, respectively $(\mathrm{p}=0.039)$ and ex-smokers had a shorter survival time compared to current smokers and non-smokers (Table 1, Fig. 1). No significant differences in PFT results, CPI values or HRCT findings were detected between the groups of different smoking histories (Table 1).

In the univariate analyses, DLco\% and CPI were significantly related to survival: for DLco\% hazard ratio (HR) was 0.97 with 95\% confidence interval (95\% CI) $0.96-0.98$ and with p-value $<0.001$ and for CPI HR was $1.04,95 \%$ CI $1.02-1.06$ and p-value $<0.001$. For that reason DLco\% and CPI were used in the severity adjustment in the multivariate analyses.

\section{Step-by-step multivariate analyses}

When survival differences were compared between exsmokers and current smokers in step-by-step multivariate analyses i.e. adding one factor at a time to the model using DLco \% and CPI in severity adjustment, the survival difference in favor of current smokers was reduced to a marginally non-significant level $(\mathrm{p}=0.098$ and $\mathrm{p}=0.128$, respectively). When age at the time of diagnosis was added into the multivariate analyses, smoking history no longer exerted any statistically significant effect on survival (Table 2). When survival differences were

Table 1 Demographics of the patients with IPF according to their smoking status

\begin{tabular}{|c|c|c|c|c|c|c|}
\hline & Whole cohort & Ex-smoker (ES) & Current smoker (CS) & Non-smoker (NS) & $\begin{array}{l}\text { p-value } \\
\text { (between ES and CS) }\end{array}$ & $\begin{array}{l}\text { p-value } \\
\text { (between ES and NS) }\end{array}$ \\
\hline$\overline{N(\%)^{a}}$ & $132(100 \%)$ & $66(50.0)$ & $17(12.8)$ & $45(34.1)$ & & \\
\hline Pack years (SD) & $25.9(17.66)$ & $23.1(18.43)$ & $32.9(13.65)$ & & 0.006 & \\
\hline Smoking years (SD) & $25.5(13.54)$ & $21.8(12.48)$ & $38.1(8.48)$ & & $<0.001$ & \\
\hline Male N (\%) & $97(73.5)$ & $59(90.8)$ & $14(82.4)$ & $20(44.4)$ & 0.312 & $<0.001$ \\
\hline Age at diagnosis (y)(SD) & $70.5(9.80)$ & $72.4(7.95)$ & $58.1(9.93)$ & $71.7(8.74)$ & $<0.001$ & 0.411 \\
\hline Age at death (y) (SD) & $74.4(9.35)$ & $75.8(8.06)$ & $63.1(8.13)$ & $76.2(8.47)$ & $<0.001$ & 0.877 \\
\hline Median survival (mo) & 45.0 & 36.0 & 52.0 & 55.0 & 0.029 & 0.034 \\
\hline \multicolumn{7}{|c|}{ Pulmonary function tests (mean (SD)) } \\
\hline $\mathrm{FVC} \%(\mathrm{SD})^{\mathrm{b}}$ & $76.7(18.51)$ & $75.6(19.51)$ & $76.1(17.48)$ & $78.3(17.26)$ & 0.926 & 0.341 \\
\hline FEV1\% (SD) & $77.0(16.99)$ & $74.9(17.64)$ & $75.1(15.77)$ & $80.7(16.26)$ & 0.866 & 0.050 \\
\hline FEV1/FVC\% (SD) & $101.4(9.68)$ & $100.0(9.70)$ & $99.8(11.84)$ & $103.7(7.72)$ & 0.995 & 0.093 \\
\hline DLCO\% $(S D)^{c}$ & $56.1(17.51)$ & $53.8(16.13)$ & 58.9 (19.49) & $58.2(18.98)$ & 0.272 & 0.139 \\
\hline CPI (SD) & 39.9 (19.96) & $41.1(13.63)$ & $37.9(14.25)$ & $39.1(14.67)$ & 0.312 & 0.341 \\
\hline \multicolumn{7}{|c|}{ Radiological diagnoses N (\%) } \\
\hline Definite UIP & $79(61.7)$ & $37(46.8)$ & $14(61.7)$ & $28(35.4)$ & 0.055 & 0.553 \\
\hline Possible UIP & $28(21.9)$ & $19(67.9)$ & $1(3.6)$ & $8(28.6)$ & 0.049 & 0.261 \\
\hline Not UIP & $21(16.4)$ & $10(47.6)$ & $2(11.8)$ & $9(42.9)$ & 0.723 & 0.794 \\
\hline
\end{tabular}

Data expressed mean (SD) or $\mathrm{N}(\%)$ of patients

$N$ number, $y$ years, mo months, FVC forced vital capacity, \% pred percent predicted, FEV1 forced expiratory volume in one second, DLco diffusion capacity of carbon monoxide, CPI composite physiologic index, UIP usual interstitial pneumonia, SD standard deviation

${ }^{a}$ smoking status of 4 patients ( 2 male and 2 female) was unknown

${ }^{b}$ Spirometry results from 126 patients

'Diffusion capacity from 124 patients 


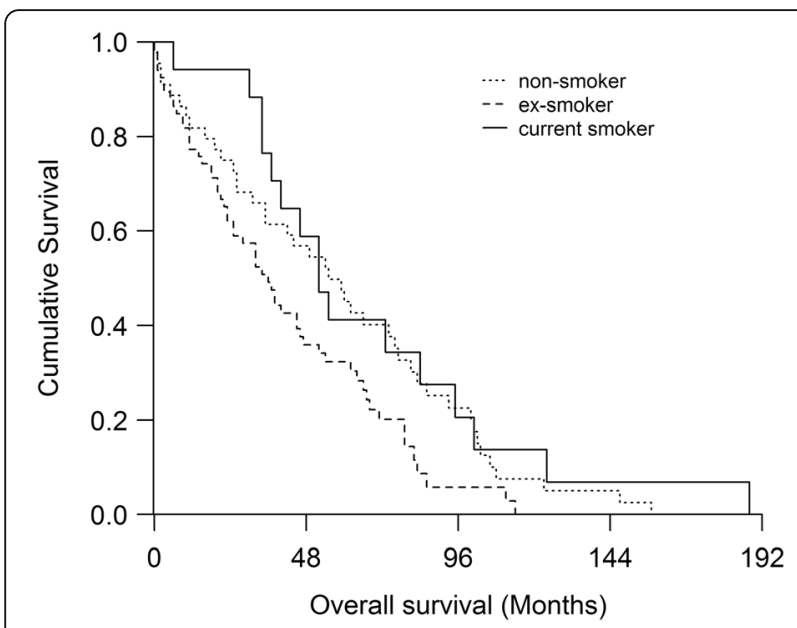

Fig. 1 Analyses of survival indicates that ex-smokers revealed shorter survival time (36 months) than current smokers (52 months (0.029)) or non-smokers (55 months $(p=0.034)$ )

compared between ex-smokers and non-smokers, the better survival of non-smokers disappeared after severity adjustment with DLco\% and CPI while age remained as a significant predictor of survival (Table 3). Male gender was found to be a significant risk factor for shorter survival when comparing ex-smokers and non-smokers, but not in the comparison between ex-smokers and current smokers (Tables 2 and 3).

\section{Comorbidities and medications}

Twenty-one (15.9\%) of the patients did not have any comorbidities while $36(27.3 \%)$ had one, $30(22.7 \%)$ had two, $20(15.2 \%)$ had three, 21 (15.9) had four and 4 (3.0\%) had five comorbidities. The most common comorbidities were cardiovascular diseases (CVDs) (72.7 \%) (Fig. 2). Females were more likely than males to suffer from asthma, hypertension or diabetes. Current smokers had significantly more COPD $(\mathrm{p}=0.000)$ and lung cancer $(\mathrm{p}=0.006)$ compared to ex-smokers, this difference was observed in males, but not in females when the data was subdivided according to genders (Table 4). The multivariate analyses were adjusted for age, gender and smoking status and in addition, DLco \% or CPI in two different models (Table 5). In multivariate analysis with DLco \%, CVD and COPD were related to poorer survival and in the multivariate analysis with CPI, it was noted that the use of insulin was related to poorer survival (Table 5). In the ordered logistic regression, age, but not smoking history, exerted a significant impact on the number of comorbidities (standardized beta coefficient 1.044, $\mathrm{p}=0.003$ ), but the number of comorbidities did not have any statistically significant effect on survival even in multivariate analyses.

Comorbidities had been most often diagnosed before IPF (Fig. 2). CVDs and CAD were more often diagnosed
Table 2 A comparison of survival between ex-smokers and current smokers in the step-by-step multivariate models

\begin{tabular}{|c|c|c|c|}
\hline & $\mathrm{HR}$ & $95 \% \mathrm{Cl}$ & $p$-value \\
\hline \multicolumn{4}{|l|}{ Univariate } \\
\hline Ex-smoker & Reference & & \\
\hline Current smoker & 0.52 & $0.29-0.95$ & 0.033 \\
\hline \multicolumn{4}{|c|}{ Model containing DLco\% } \\
\hline Ex-smoker & Reference & & \\
\hline Current smoker & 0.60 & $0.33-1.10$ & 0.098 \\
\hline Dlco\% & 0.97 & $0.96-0.99$ & 0.001 \\
\hline \multicolumn{4}{|c|}{ Model containing CPI } \\
\hline Ex-smoker & Reference & & \\
\hline Current smoker & 0.62 & $0.34-1.14$ & 0.126 \\
\hline $\mathrm{CPI}$ & 1.03 & $1.01-1.05$ & 0.001 \\
\hline
\end{tabular}

Model containing DLco \% and age

$\begin{array}{llll}\text { Ex-smoker } & \text { Reference } & & \\ \text { Current smoker } & 1.32 & 062-2.72 & 0.472 \\ \text { Dlco\% } & 0.97 & 0.95-0.98 & <0.001 \\ \text { Age at diagnosis } & 1.06 & 1.02-1.10 & 0.001\end{array}$

Model containing CPI and age

$\begin{array}{llll}\text { Ex-smoker } & \text { Reference } & & \\ \text { Current smoker } & 1.63 & 0.75-3.54 & 0.217 \\ \text { CPI } & 1.05 & 1.02-1.07 & <0.001 \\ \text { Age at diagnosis } & 1.07 & 1.03-1.12 & <0.001 \\ \text { Model containing DLco \%, age and gender } & & \\ \text { Ex-smoker } & \text { Reference } & & \\ \text { Current smoker } & 1.32 & 063-2.80 & 0.465 \\ \text { Dlco\% } & 0.97 & 0.95-0.99 & <0.001 \\ \text { Age at diagnosis } & 1.06 & 1.03-1.10 & 0.001 \\ \text { Gender - female } & \text { Reference } & & \\ \text { male } & 1.10 & 0.45-2.69 & 0.831\end{array}$

Model containing CPI, age and gender

\begin{tabular}{llll} 
Ex-smoker & Reference & & \\
Current smoker & 1.66 & $0.76-3.64$ & 0.203 \\
CPI & 1.05 & $1.02-1.07$ & $<0.001$ \\
Age at diagnosis & 1.07 & $1.03-1.12$ & $<0.001$ \\
Gender - female & Reference & & \\
male & 1.22 & $0.51-2.94$ & 0.657 \\
\hline
\end{tabular}

$H R$ hazard ratio, $C l$ confidence interval, DLco diffusion capacity of carbon monoxide, $\mathrm{CPI}$ composite physiologic index

before IPF in ex-smokers compared to current smokers ( $\mathrm{p}<0.001$, for both) and non-smokers $(\mathrm{p}=0.011$ and $\mathrm{p}=0.016$, respectively). CVDs were also more likely to be diagnosed before IPF in non-smokers than in current smokers $(\mathrm{p}=0.044)$ and in non-smoking males in comparison to male ex-smokers $(p=0.002)$. Nonsmokers $(\mathrm{p}=0.046)$ and ex-smokers $(\mathrm{p}=0.001)$ had 
Table 3 A comparison of survival between ex-smokers and non-smokers in the step-by-step multivariate models

\begin{tabular}{llll}
\hline & $\mathrm{HR}$ & $95 \% \mathrm{Cl}$ & $\mathrm{p}$-value \\
\hline Univariate & & & \\
Ex-smoker & Reference & & \\
Non-smoker & 0.64 & $0.42-0.97$ & 0.037 \\
Model containing DLco\% & & & \\
Ex-smoker & Reference & & \\
Non-smoker & 0.79 & $0.50-1.24$ & 0.306 \\
Dlco\% & 0.97 & $0.95-0.98$ & $<0.001$
\end{tabular}

Model containing CPI

$\begin{array}{llll}\text { Ex-smoker } & \text { Reference } & & \\ \text { Non-smoker } & 0.75 & 0.48-1.17 & 0.197 \\ \text { CPI } & 1.04 & 1.02-1.06 & <0.001\end{array}$

Model containing DLCO \% and age

$\begin{array}{llll}\text { Ex-smoker } & \text { Reference } & & \\ \text { Non-smoker } & 0.82 & 0.52-1.27 & 0.371 \\ \text { Dlco\% } & 0.96 & 0.95-0.98 & <0.001 \\ \text { Age at diagnosis } & 1.05 & 1.02-1.08 & 0.001\end{array}$

Model containing CPI and age

$\begin{array}{llll}\text { Ex-smoker } & \text { Reference } & & \\ \text { Non-smoker } & 0.79 & 0.51-1.23 & 0.292 \\ \text { CPI } & 1.05 & 1.03-1.07 & <0.001 \\ \text { Age at diagnosis } & 1.06 & 1.03-1.09 & <0.001 \\ \text { Model containing DLco \%, age and gender } & & \\ \text { Ex-smoker } & \text { Reference } & & \\ \text { Non-smoker } & 1.32 & 0.76-2.30 & 0.324 \\ \text { Dlco\% } & 0.96 & 0.95-0.98 & <0.001 \\ \text { Age at diagnosis } & 1.06 & 1.03-1.09 & <0.001 \\ \text { Gender - female } & \text { Reference } & & \\ \text { male } & 2.35 & 1.24-4.45 & 0.009\end{array}$

Model containing CPI, age and gender

\begin{tabular}{llll} 
Ex-smoker & Reference & & \\
Non-smoker & 1.22 & $0.71-2.10$ & 0.472 \\
CPI & 1.05 & $1.03-1.07$ & $<0.001$ \\
Age at diagnosis & 1.07 & $1.04-1.10$ & $<0.001$ \\
Gender - female & Reference & & \\
male & 2.22 & $1.18-4.18$ & 0.013 \\
\hline
\end{tabular}

$H R$ hazard ratio, $\mathrm{Cl}$ confidence interval, DLco diffusion capacity of carbon monoxide, $C P I$ composite physiologic index

received a GER diagnosis more often before the diagnosis of IPF compared to current smokers $(\mathrm{p}=0.046$ and 0.001 , respectively). After adjustment for age, smoking status, gender and separately both DLco \% and CPI, it was found that the time of the comorbidity diagnosis in relation to the IPF diagnosis did not have any effect on survival.
Pharmacological treatments for IPF are presented in Table 6, symptomatic medical treatment in Table 7 and medications for comorbidities in Table 8.

\section{Discussion}

The smoking habits in conjunction with gender, clinical characteristics and comorbidities were studied in this retrospective real-life IPF population revealing that exsmokers had a shorter survival time compared to nonsmokers and current smokers. Furthermore, current smokers were significantly younger at diagnosis and at death than non-smokers and ex-smokers, but no differences in the major comorbidities i.e. CVD, CAD, hypertension, diabetes were found in relation to smoking history. Current smokers, who had smoked for more years and had more pack-years than ex-smokers, had more smoking-associated comorbidities such as COPD and lung cancer.

The results of our study confirm the findings of the previous studies in which unadjusted survival time was longer in current smokers and in non-smokers than in ex-smokers and similarly severity adjustment eliminated the survival advantage [2, 3]. We also observed that at the time of IPF-diagnosis, current smokers were significantly younger than either non-smokers or ex-smokers, a finding in agreement with several published studies $[2,3]$. When compared to previous studies, however, exsmokers and non-smokers were remarkably older but had better preserved lung function [1-3]. In our study however, despite the younger age of current smokers, the PFT and CPI did not differ between the groups of different smoking histories, although current smokers had smoked significantly more years and pack-years compared to ex-smokers. When comparing the severity adjusted survival of current smokers and ex-smokers, there was still a marginal non-significant survival advantage for current smokers but this became diminished when age was added into the model. This may be due to under-powering i.e. the low number of patients, but it is however noteworthy that the proportion of current smokers was higher $(13 \%)$ in our study than in the publication of Antoniou et al. (8\%) in which a survival difference was abolished when CPI was incorporated into the severity adjustment [2].

Differences in the proportions of current smokers, non-smokers and ex-smokers can be seen in published studies from different countries. In our study, $35.2 \%$ of the patients with IPF were non-smokers. In the Finnish IPF register, in which the patients are collected prospectively including patients from the year 2012 onwards, as many as $44 \%$ of the patients were non-smokers [23]. However, the registry includes only patients who have provided consent to participate, meaning that the IPF patients with rapidly progressing disease or older age 


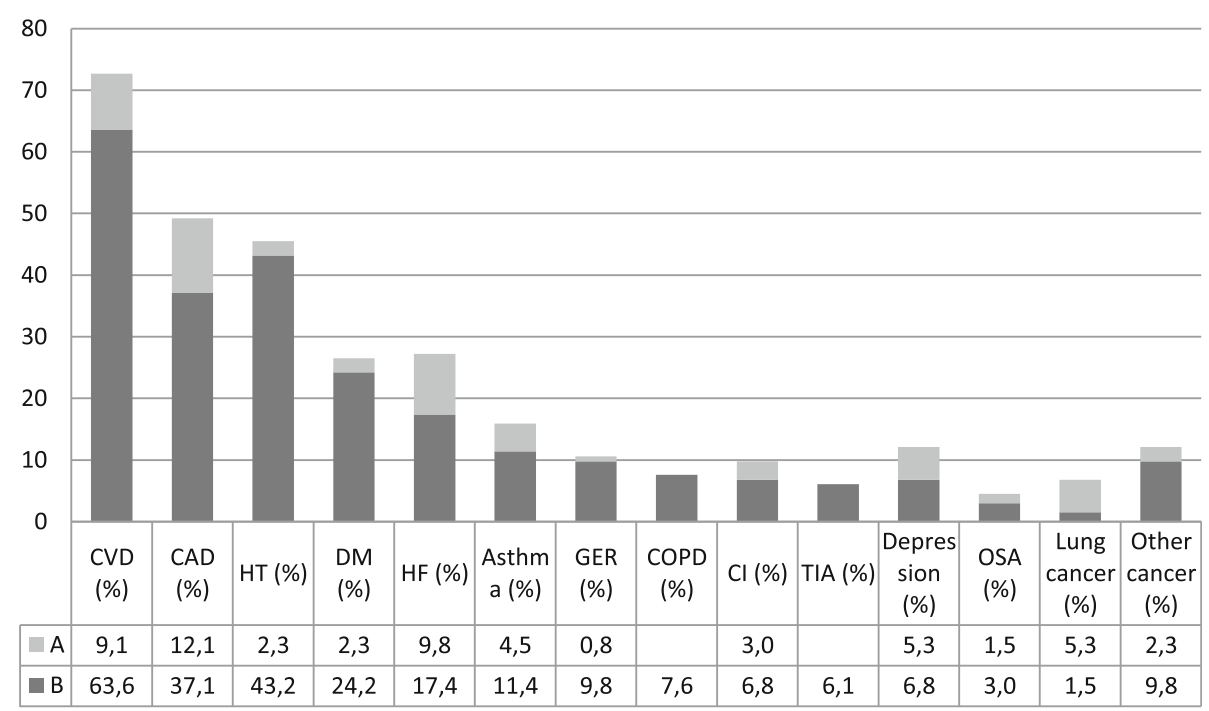

Fig. 2 Prevalence of comorbidities in the IPF patients are presented as percent of total $(N=132)$. The time of comorbidity diagnoses are presented before and after the diagnosis of IPF. CVD includes CAD, HT and Cl. B, diagnosed before the diagnosis of IPF; A, diagnosed after the diagnosis of IPF; $C V D$, cardiovascular disease; $C A D$, coronary artery disease; $H T$, hypertension; $D M$, diabetes; $H F$, heart failure for any reason; GER, gastro-esophageal reflux; COPD, chronic obstructive pulmonary disease; Cl, cerebral infarction; TIA, transient ischemic attack; OSA, obstructive sleep apnea. Other cancers treated before the diagnosis of IPF included seminoma, melanoma, basal cell carcinoma, renal, ventricular, prostate, bone, colorectal, breast and thyroid cancer. One patient had three different cancers. Two colorectal cancers were detected after the diagnosis of IPF

and with cognitive impairment have not been taken into account. The percentage of non-smokers is surprisingly different in these Finnish studies compared to the results of one other Nordic country, i.e. Denmark, in which only $19 \%$ of the patients were non-smokers in a similar size of cohort $(\mathrm{n}=121)$ as ours [10]. This may be due to cultural differences and also the reason why the "healthy smoker effect" was not displayed in our study. The "healthy smoker effect" is a term originating from COPD studies; it has been used to explain why current smokers exhibit milder disease than non-smokers and exsmokers in terms of PFT, DLco and CPI [2, 24]. This effect was not confirmed in our IPF population.

King et al. claimed that current smokers had a longer survival than ex-smokers [3]. Current smokers were younger compared to those with other smoking histories which meant that age was found to be a significant predictor of survival [3]. This study disagrees with the study

Table 4 Comorbidities of patients with IPF according to their smoking habits

\begin{tabular}{|c|c|c|c|c|}
\hline & Non-smokers & Ex-smokers & Current smokers & $p$-value \\
\hline Cardiovascular diseases $^{a}$ & 34 (75.6) & $46(69.7)$ & $12(70.6)$ & 0.790 \\
\hline Coronary artery disease & $22(48.9)$ & $29(43.9)$ & $10(58.8)$ & 0.537 \\
\hline Hypertension & $23(51.1)$ & $28(42.4)$ & $6(35.3)$ & 0.474 \\
\hline Cerebral infarction & $3(6.7)$ & $8(12.1)$ & $2(11.8)$ & 0.629 \\
\hline TIA & $3(6.7)$ & $5(7.6)$ & & 0.511 \\
\hline Diabetes & $13(28.9)$ & $18(27.3)$ & $1(6.3)$ & 0.145 \\
\hline Heart failure ${ }^{b}$ & $16(35.6)$ & $14(21.2)$ & $3(17.6)$ & 0.169 \\
\hline Asthma & $7(15.6)$ & $9(13.6)$ & $4(23.5)$ & 0.605 \\
\hline Depression & $4(8.9)$ & $4(6.1)$ & $1(6.3)$ & 0.832 \\
\hline GER & $3(6.7)$ & $10(15.2)$ & $1(6.3)$ & 0.288 \\
\hline Lung cancer & & $4(6.1)$ & $5(29.4)$ & $<0.001$ \\
\hline COPD & & $3(4.5)$ & $7(41.2)$ & $<0.001$ \\
\hline OSA & $2(4.4)$ & $3(4.5)$ & $1(6.3)$ & 0.969 \\
\hline
\end{tabular}

$N$ number, NS p-value $>0.05, T I A$ transient ischemic attack, GER gastro-esophageal reflux, COPD chronic obstructive pulmonary disease, OSA obstructive sleep apnea

${ }^{a}$ Coronary artery disease, cerebral infarction and hypertension

${ }^{b}$ Heart failure for any reason 
Table 5 Comorbidities and their association with survival after adjustment for age, smoking status, gender and DLCO\% or CPI

\begin{tabular}{|c|c|c|c|c|c|}
\hline & & Multivariate with & & Multivariate with & \\
\hline & $N(\%)$ & HR $(95 \% \mathrm{Cl})$ & $p$-value & HR (95\% C I) & p-value \\
\hline Cardiovascular diseases ${ }^{b}$ & $96(72.7)$ & $1.6(1.01-2.52)$ & 0.047 & $1.5(0.94-2.38)$ & 0.086 \\
\hline Coronary artery disease & $65(49.2)$ & $1.4(0.92-2.05)$ & 0.124 & $1.4(0.93-2.10)$ & 0.109 \\
\hline Hypertension & $60(45.5)$ & $1.0(0.69-1.52)$ & 0.900 & $1.0(0.67-1.47)$ & 0.955 \\
\hline Heart failure ${ }^{c}$ & $36(27.2)$ & $0.8(053-1.25)$ & 0.339 & $0.8(0.53-1.27)$ & 0.378 \\
\hline Cerebral infarction & $13(9.8)$ & $0.8(0.40-1.44)$ & 0.395 & $0.9(0.45-1.63)$ & 0.638 \\
\hline TIA & $8(6.1)$ & $1.1(0.48-2.66)$ & 0.778 & $1.2(0.52-2.89)$ & 0.648 \\
\hline Diabetes & $35(26.5)$ & $1.3(0.82-2.11)$ & 0.256 & $1.4(1.03-1.07)$ & 0.198 \\
\hline OSA & $6(4.5)$ & $0.5(0.22-1.20)$ & 0.121 & $0.5(0.21-1.59)$ & 0.105 \\
\hline GER & $14(10.6)$ & $0.9(0.49-1.74)$ & 0.799 & $0.9(0.46-1.64)$ & 0.661 \\
\hline Asthma & $21(15.9)$ & $1.6(0.92-2.78)$ & 0.098 & $1.5(0.89-2.66)$ & 0.126 \\
\hline COPD & $10(7.6)$ & $2.5(1.02-6.01)$ & 0.045 & $1.8(0.78-4.27)$ & 0.163 \\
\hline Lung cancer & $9(6.8)$ & $1.0(0.48-2.15)$ & 0.965 & $0.9(0.43-1.92)$ & 0.808 \\
\hline Depression & $10(7.6)$ & $0.9(0.43-2.06)$ & 0.880 & $0.8(0.39-1.81)$ & 0.654 \\
\hline Medications & & & & & \\
\hline Statins & $56(42.4)$ & $1.3(0.85-2.06)$ & 0.215 & $1.4(0.91-2.25)$ & 0.121 \\
\hline Beta-blockers & $57(43.2)$ & $0.9(0.58-1.35)$ & 0.566 & $0.9(0.59-1.39)$ & 0.643 \\
\hline GER medication & $13(9.8)$ & $0.9(0.48-1.71)$ & 0.752 & $1.2(0.64-2.28)$ & 0.556 \\
\hline ACE inhibitors or angiotensin 1 antagonists & $48(36.4)$ & $1.4(0.94-2.04)$ & 0.103 & $1.1(0.70-1.66)$ & 0.737 \\
\hline Anticoagulants & $15(11.4)$ & $1.1(0.59-1.89)$ & 0.849 & $0.7(0.39-1.37)$ & 0.332 \\
\hline Platelet function drugs ${ }^{d}$ & $58(43.9)$ & $1.2(0.77-1.88)$ & 0.420 & $1.3(0.82-2.04)$ & 0.277 \\
\hline Inhaled corticosteroids & $12(9.1)$ & $1.4(0.71-2.83)$ & 0.327 & $1.0(1.03-1.07)$ & 0.290 \\
\hline Antidiabetic drugs ${ }^{e}$ & $22(16.7)$ & $1.6(0.88-2.84)$ & 0.123 & $1.7(0.94-3.03)$ & 0.082 \\
\hline Insulin & $9(6.8)$ & $2.4(0.95-6.24)$ & 0.063 & $2.8(1.07-7.09)$ & 0.036 \\
\hline Thyroid medication & $16(12.1)$ & $0.9(0.49-1.81)$ & 0.858 & $1.0(0.50-1.90)$ & 0.946 \\
\hline Allopurinol & $4(3.0)$ & $0.8(0.18-3.21)$ & 0.717 & $0.6(0.14-2.37)$ & 0.439 \\
\hline
\end{tabular}

$N$ number, SD standard deviation, $95 \%$ C I 95 percent confidence interval, HRCT high resolution computed tomography, UIP usual interstitial pneumonia, TIA transient ischemic attack, OSA obstructive sleep apnea, GER gastro-esophageal reflux, COPD chronic obstructive pulmonary disease

${ }^{a}$ Adjusted for age, gender and smoking history and DLCO\% or CPI

${ }^{\mathrm{b} C}$ Coronary artery disease, hypertension and cerebral infarction

${ }^{\mathrm{C}}$ Heart failure for any reason

${ }^{\mathrm{d} A c e t y l s a l i c y l i c ~ a c i d, ~ d i p y r i d a m o l e ~ a n d ~ c l o p i d o g r e l ~}$

e Metformin, glimepiride and sitagliptin

of King et al. since ex-smokers and non-smokers were remarkably older at the time of diagnosis and furthermore, no significant differences in the PFT and DLco results were observed. The reason why non-smokers and ex-smokers were about 10 years older at the time of diagnosis in this study compared to previous studies is uncertain but may partly explain the reason why current smokers exhibited a longer survival $[2,3]$.

A more recent study comparing non-smoking IPF patients to a combined group of ex-smokers and current smokers confirmed our results of non-smokers being mostly female, but found no difference in age between the groups [4]. In that particular study, non-smokers had significantly worse survival, lower DLco and higher CPI and even adjusted for CPI, the poorer prognosis of non-smokers was retained and baseline CPI, DLco\% and FVC \% were not statistically significantly predictive for survival, a finding which is different from that of Antoniou's et al. [2, 4].

In our study, the HRCT classification was performed according to the present guidelines [22]. We found that the most common pattern in HRCT in non-smokers was definite UIP in agreement with previous reports $[4,22]$. Our results are also in line with the previous publications showing that non-smokers accounted for $35.4 \%$ of the definite UIP patterns in HRCT. Furthermore, the gender distribution between the different radiological categories was similar as in other reports $[25,26]$.

The prevalences of GER, lung cancer, COPD, hypertension, $\mathrm{CAD}$ and diabetes were in line with most 
Table 6 Pharmacological treatment of IPF in the years 2002 $2016^{\mathrm{a}}$

\begin{tabular}{|c|c|}
\hline Medication & $\mathrm{N} / \%$ \\
\hline No medication & $42 / 31.8$ \\
\hline \multicolumn{2}{|l|}{ Total } \\
\hline Corticosteroids & $75 / 56.8$ \\
\hline Azathioprine & $28 / 37.2$ \\
\hline N-acetylcysteine & $30 / 40.0$ \\
\hline Cyclophosphamide & $16 / 12.1$ \\
\hline Pirfenidone & $6 / 4.5$ \\
\hline Nintedanib & $3 / 2.3$ \\
\hline Mycophenolate mofetil & $1 / 0.8$ \\
\hline \multicolumn{2}{|l|}{ Single medication } \\
\hline Corticosteroids & $24 / 18.2$ \\
\hline N-acetylcysteine & $11 / 8.3$ \\
\hline Pirfenidone & $5 / 3.8$ \\
\hline Nintedanib & $1 / 0.8$ \\
\hline Triple therapy ${ }^{b}$ & $7 / 5.3$ \\
\hline \multicolumn{2}{|c|}{ Combined with prednisone as only medication } \\
\hline Azathioprine & $14 / 10.6$ \\
\hline N-acetylcysteine & $13 / 9.8$ \\
\hline Cyclophosphamide & $8 / 6.1$ \\
\hline \multicolumn{2}{|l|}{ After prednisone therapy } \\
\hline Nintedanib & $2 / 1.5$ \\
\hline \multicolumn{2}{|l|}{ Before triple therapy } \\
\hline Cyclophosphamide + Corticosteroids & $2 / 1.5$ \\
\hline \multicolumn{2}{|l|}{ After triple therapy } \\
\hline Pirfenidone & $1 / 0.8$ \\
\hline Cyclophosphamide & $3 / 2.3$ \\
\hline Mycophenolate & $1 / 0.8$ \\
\hline
\end{tabular}

Diagnosis of IPF between years 2002 - 2012, while the follow-up information of medication was gathered until 16.10.2016. Reimbursement (by KELA) in Finland for pirfenidone in $1^{\text {st }}$ June 2013 and for nintedanib in $1^{\text {st }}$ December 2015.

${ }^{\mathrm{b}}$ Triple therapy = azathioprine, $\mathrm{N}$-acetylcysteine and prednisone

previous publications, although OSA was less frequent $(4.5 \%)$ in our cohort $[6,7,27]$. Our results support the earlier findings that CVDs are the most common comorbidities experienced by IPF patients [7, 28]. It has been reported that the overall number of comorbidities is significantly associated with survival in IPF, but this was not the case in our patients [6]. IPF patients with CAD have been reported to have worse outcomes [12]. If CVDs were diagnosed after the diagnosis of IPF, this was associated with increased mortality in IPF as was also the presence of either diabetes or thyroid disease [11]. In contrast, in our study, diabetes, thyroid medication and CAD alone did not influence survival, and furthermore, the CVDs and CAD had been most often diagnosed before the diagnosis of IPF. This may be caused by the
Table 7 Symptomatic medical treatment for IPF

\begin{tabular}{ll}
\hline Medication & $\mathrm{N} / \%$ \\
\hline Opioids $^{\text {a }}$ & $27 / 20.5$ \\
Oxygen therapy & $45 / 34.1$ \\
Ambulatory & $17 / 37.7$ \\
Long term & $28 / 21.1$ \\
Inhaled corticosteroids & $9 / 6.8$ \\
Short-acting beta-agonists & $7 / 5.3$ \\
Anticholinergic drugs & $2 / 1.5$ \\
Theophylline & $1 / 0.8$ \\
Montelukast & $1 / 0.8$ \\
Mycolytics & $3 / 2.3$ \\
\hline a Oxycodone, Fentanyl &
\end{tabular}
[29]. However, the diagnosis of any CVD and COPD at any time and the use of insulin medication at the time of diagnosis were related to poorer survival in the severity adjusted analyses. Our results revealed no effect of statin and anticoagulant medication on survival in IPF unlike previously published investigations [6, 16-19]. The use of GER medication and a GER diagnosis have been associated with longer survival times in some previous investigations, but here, they exerted no effect on survival $[6,15]$.

In this study cohort, female IPF patients had more asthma and diabetes than their male counterparts. Current smokers had more COPD and lung cancer compared to ex-smokers probably due to the fact that current smokers had smoked more than ex-smokers in terms of both years and in pack-years. When comparing the subgroups with different smoking histories, surprisingly, no statistically significant differences were detected in the proportion of patients with CVD, CAD or GER as

Table 8 Medications for comorbidities

\begin{tabular}{ll}
\hline Medication & $\mathrm{N}(\%)$ \\
\hline Statins & $56(42.4)$ \\
Beta-blockers & $57(43.2)$ \\
ACE inhibitors or angiotensin 1 antagonist & $48(36.4)$ \\
GER medication & $13(9.8)$ \\
Allopurinol & $4(3.0)$ \\
Anticoagulants & $15(11.4)$ \\
Antiplatelet therapy $^{\text {a }}$ & $58(43.9)$ \\
Inhaled corticosteroids $^{\text {Antidiabetic drugs }}{ }^{\text {b }}$ & $12(9.1)$ \\
Insulin & $22(16.7)$ \\
Thyroid medication & $9(6.8)$ \\
\hline
\end{tabular}

$N$ number of patients with the medication

${ }^{a}$ Acetylsalicylic acid, dipyridamole and clopidogrel

${ }^{\mathrm{b}}$ Metformin, glimepiride and sitagliptin 
comorbidity. In this study, we could not prove that smoking history had any significant effect on major comorbidities or their prevalence, and even although older age seemed to add to the number of comorbidities, the quality and severity of the comorbidity were probably more important than the actual number of comorbidities.

\section{Conclusions}

It can be speculated that smoking may, at least partly, influence the onset of IPF since current smokers developed the disease earlier and died at a younger age than either non-smokers or ex-smokers. No significant differences in the major comorbidities were found between IPF patients with different smoking histories.

\section{Abbreviations \\ ATS: American Thoracic Society; CAD: coronary artery disease; COPD: chronic obstructive pulmonary disease; CPI: composite physiologic index; CVD: cardiovascular disease; DLco: diffusion capacity of carbon monoxide; DLco/NA: potential value of diffusion capacity per liter of lung volume; ERS: European Respiratory Society; FEV1: forced expiratory volume in one second; FEV1/FVC: forced expiratory volume in one second and forced vital capacity ratio; FVC: forced vital capacity; GER: gastro-esophageal reflux; HRCT: high resolution computed tomography; ICD-10: International Classification of Diseases version 10; IPF: Idiopathic pulmonary fibrosis; PFT: pulmonary function tests; UIP: usual interstitial pneumonia}

\section{Acknowledgements}

The authors wish to thank Ewen MacDonald for providing assistance with the grammar and style.

\section{Funding}

M. K. has received grants for scientific work from the Foundation of the Finnish Anti-Tuberculosis Association, the Organization for Respiratory Health in Finland, the Väinö and Laina Kivi Foundation, the Kuopio Region Respiratory Foundation and the Jalmari and Rauha Ahokas Foundation; H.N. has received grants for scientific work from the Foundation of the Finnish Anti-Tuberculosis Association, the Organization for Respiratory Health in Finland, the Väinö and Laina Kivi Foundation, the Kuopio Region Respiratory Foundation and the Jalmari and Rauha Ahokas Foundation; M.P. received grants for scientific work from the Research Director of Kuopio University Hospital, the Foundation of the Finnish Anti-Tuberculosis Association and the Jalmari and Rauha Ahokas Foundation; R. $K$. has received grants for scientific work and for the research team from the state subsidy of Kuopio University Hospital, the Foundation of The Finnish AntiTuberculosis Association and the Kuopio Region Respiratory Foundation.

\section{Availability of data and materials}

The datasets generated during and analyzed during the current study are not publicly available due to the relatively small population of eastern Finland since we could not guarantee individuals' anonymity as the data was collected in a detailed manner, but it is available from the corresponding author on reasonable request.

\section{Authors' contributions}

MK collected the study material, analyzed the data and takes responsibility for the integrity of the data and accuracy of the data analysis and prepared the draft of the manuscript. H-PK planned the radiological data collection form and performed the radiological analyzes. HN participated in the interpretation of the data and the presentation of the results. TS participated on the statistical analyses. MP contributed to the study design, planning of the data collection form and data interpretation. RK managed and designed the study, planned the data collection form and interpreted the data. All authors participated in the preparation of the manuscript, read and approved the final manuscript.

\section{Ethics approval and consent to participate}

The study protocol was approved by the Ethical Committee of $\mathrm{KUH}$ (statement 17/2013)

\section{Consent for publication}

No consents for the participation and publication were gathered since this was a retrospective study and majority of the patients are deceased.

\section{Competing interests}

M.K. has received congress travel grants from Intermune, BoehringerIngelheim, Orion Pharma and Roche; lecture fee from Boehringer-Ingelheim; $\mathrm{H}$-P.K. received consulting fees from Siemens and Roche Oy; $\mathrm{H}$. N. has received congress travel grants from Boehringer-Ingelheim, Lilly Oncology, Novartis, Orion Pharma and GlaxoSmithKline; Consulting fees from Boehringer-Ingelheim and Roche Oy; M. P. has received travel grants from Boehringer-Ingelheim Finland Ltd, Takeda Leiras Ltd, Roche, personal fees from Boehringer-Ingelheim Finland Ltd, Chiesi, Intermune, Orion Pharma Ltd, Roche, Takeda Leiras Ltd; T.S. has no conflicts of interest; R.K. has received congress and meeting travel grants from Intermune, Roche, BoehringerIngelheim and Orion, and a consulting fee from GSK.

\section{Publisher's Note}

Springer Nature remains neutral with regard to jurisdictional claims in published maps and institutional affiliations.

\section{Author details}

${ }^{1}$ The Center of Medicine and Clinical Research, Division of Respiratory Medicine, Kuopio University Hospital, P.O. Box 100, 70029 KYS,

Puijonlaaksontie 2, 70210 Kuopio, Finland. 'Division of Respiratory Medicine, Institute of Clinical Medicine, School of Medicine, Faculty of Health Sciences, University of Eastern Finland, P.O. Box 1627, 70211 Kuopio, Finland. ${ }^{3}$ Department of Clinical Radiology, Kuopio University Hospital, P.O. Box 100, 70029 KYS Kuopio, Finland. ${ }^{4}$ Harjula Hospital, the Municipal Hospital of Kuopio, Niuvantie 4, 70101 Kuopio, Finland. ${ }^{5}$ The Science Services Center, Kuopio University Hospital, P.O. Box 100, 70029 KYS Kuopio, Finland. ${ }^{6}$ Respiratory Medicine, Internal Medicine Research Unit, Medical Research Center Oulu, Oulu University Hospital and University of Oulu, P.O. Box 20, 90029 Oulu, Finland.

Received: 25 December 2016 Accepted: 13 August 2017

Published online: 22 August 2017

\section{References}

1. Baumgartner KB, Samet JM, Stidley CA, Colby TV, Waldron JA. Cigarette smoking: a risk factor for idiopathic pulmonary fibrosis. Am J Respir Crit Care Med. 1997:155(1):242-8.

2. Antoniou KM, Hansell DM, Rubens MB, Marten K, Desai SR, Siafakas NM, et al. Idiopathic pulmonary fibrosis: outcome in relation to smoking status. Am J Respir Crit Care Med. 2008;177(2):190-4.

3. King TE Jr, Tooze JA, Schwarz MI, Brown KR, Cherniack RM. Predicting survival in idiopathic pulmonary fibrosis: scoring system and survival model. Am J Respir Crit Care Med. 2001;164(7):1171-81.

4. Kishaba T, Nagano H, Nei Y, Yamashiro S. Clinical characteristics of idiopathic pulmonary fibrosis patients according to their smoking status. J Thorac Dis. 2016;8(6):1112-20.

5. Ekstrom M, Gustafson T, Boman K, Nilsson K, Tornling G, Murgia N, et al. Effects of smoking, gender and occupational exposure on the risk of severe pulmonary fibrosis: a population-based case-control study. BMJ Open. 2014; 4(1):e004018,2013-004018.

6. Kreuter M, Ehlers-Tenenbaum S, Palmowski K, Bruhwyler J, Oltmanns U, Muley T, et al. Impact of Comorbidities on Mortality in Patients with Idiopathic Pulmonary Fibrosis. PLoS One. 2016;11(3):e0151425.

7. Raghu G, Amatto VC, Behr J, Stowasser S. Comorbidities in idiopathic pulmonary fibrosis patients: a systematic literature review. Eur Respir J. 2015; 46(4):1113-30.

8. Kim WY, Mok Y, Kim GW, Baek SJ, Yun YD, Jee SH, et al. Association between idiopathic pulmonary fibrosis and coronary artery disease: a casecontrol study and cohort analysis. Sarcoidosis Vasc Diffuse Lung Dis. 2015; 31(4):289-96. 
9. Hubbard RB, Smith C, Le Jeune I, Gribbin J, Fogarty AW. The association between idiopathic pulmonary fibrosis and vascular disease: a populationbased study. Am J Respir Crit Care Med. 2008;178(12):1257-61.

10. Hyldgaard C, Hilberg O, Bendstrup E. How does comorbidity influence survival in idiopathic pulmonary fibrosis? Respir Med. 2014;108(4):647-53.

11. Oldham JM, Kumar D, Lee C, Patel SB, Takahashi-Manns S, Demchuk C, et al. Thyroid Disease Is Prevalent and Predicts Survival in Patients With Idiopathic Pulmonary Fibrosis. Chest. 2015;148(3):692-700.

12. Nathan SD, Basavaraj A, Reichner C, Shlobin OA, Ahmad S, Kiernan J, et al. Prevalence and impact of coronary artery disease in idiopathic pulmonary fibrosis. Respir Med. 2010;104(7):1035-41.

13. Lee T, Park JY, Lee HY, Cho YJ, Yoon HI, Lee JH, et al. Lung cancer in patients with idiopathic pulmonary fibrosis: clinical characteristics and impact on survival. Respir Med. 2014;108(10):1549-55.

14. Tomassetti S, Gurioli C, Ryu JH, Decker PA, Ravaglia C, Tantalocco P, et al. The impact of lung cancer on survival of idiopathic pulmonary fibrosis. Chest. 2015;147(1):157-64.

15. Lee JS, Ryu JH, Elicker BM, Lydell CP, Jones KD, Wolters PJ, et al. Gastroesophageal reflux therapy is associated with longer survival in patients with idiopathic pulmonary fibrosis. Am J Respir Crit Care Med 2011;184(12):1390-4.

16. Kreuter M, Bonella F, Maher TM, Costabel U, Spagnolo P, Weycker D, et al. Effect of statins on disease-related outcomes in patients with idiopathic pulmonary fibrosis. Thorax. 2016;

17. Nadrous HF, Ryu JH, Douglas WW, Decker PA, Olson EJ. Impact of angiotensin-converting enzyme inhibitors and statins on survival in idiopathic pulmonary fibrosis. Chest. 2004;126(2):438-46.

18. Kreuter M, Wijsenbeek MS, Vasakova M, Spagnolo P, Kolb M, Costabel U, et al. Unfavourable effects of medically indicated oral anticoagulants on survival in idiopathic pulmonary fibrosis. Eur Respir J. 2016;47(6):1776-84.

19. Tomassetti S, Ruy JH, Gurioli C, Ravaglia C, Buccioli M, Tantalocco P, et al. The effect of anticoagulant therapy for idiopathic pulmonary fibrosis in real life practice. Sarcoidosis Vasc Diffuse Lung Dis. 2013:30(2):121-7.

20. Viljanen AA, Halttunen PK, Kreus KE, Viljanen BC. Spirometric studies in nonsmoking, healthy adults. Scand J Clin Lab Invest Suppl. 1982;159:5-20.

21. Wells AU, Desai SR, Rubens MB, Goh NS, Cramer D, Nicholson AG, et al. Idiopathic pulmonary fibrosis: a composite physiologic index derived from disease extent observed by computed tomography. Am J Respir Crit Care Med. 2003;167(7):962-9.

22. Raghu G, Collard HR, Egan JJ, Martinez FJ, Behr J, Brown KK, et al. An official ATS/ERS/JRS/ALAT statement: idiopathic pulmonary fibrosis: evidence-based guidelines for diagnosis and management. Am J Respir Crit Care Med. 2011; 183(6):788-824.

23. Kaunisto J, Kelloniemi K, Sutinen E, Hodgson U, Piilonen A, Kaarteenaho R, et al. Re-evaluation of diagnostic parameters is crucial for obtaining accurate data on idiopathic pulmonary fibrosis. BMC Pulm Med. 2015;15: 92,015-0074-3

24. Bednarek M, Gorecka D, Wielgomas J, Czajkowska-Malinowska M, Regula J, Mieszko-Filipczyk G, et al. Smokers with airway obstruction are more likely to quit smoking. Thorax. 2006;61(10):869-73.

25. Lee JW, Shehu E, Gjonbrataj J, Bahn YE, Rho BH, Lee MY, et al. Clinical findings and outcomes in patients with possible usual interstitial pneumonia. Respir Med. 2015;109(4):510-6.

26. Le Rouzic O, Bendaoud S, Chenivesse C, Remy J, Wallaert B. Prognostic value of the initial chest high-resolution $C T$ pattern in idiopathic pulmonary fibrosis. Sarcoidosis Vasc Diffuse Lung Dis. 2016;32(4):353-9.

27. Kim ES, Choi SM, Lee J, Park YS, Lee CH, Yim JJ, et al. Validation of the GAP score in Korean patients with idiopathic pulmonary fibrosis. Chest. 2015; 147(2):430-7.

28. Vancheri C, Cottin V, Kreuter M, Hilberg O. IPF, comorbidities and management implications. Sarcoidosis Vasc Diffuse Lung Dis. 2015:32(1 Suppl):17-23.

29. http://urn.fi/URN:NBN:fi-fe2016111829194 